\title{
The epidemiology of osteonecrosis: findings from the GPRD and THIN databases in the UK
}

\author{
C. Cooper • M. Steinbuch $\cdot$ R. Stevenson • R. Miday • \\ N. B. Watts
}

Received: 6 April 2009 / Accepted: 22 May 2009/Published online: 23 June 2009

(C) The Author(s) 2009. This article is published with open access at Springerlink.com

\begin{abstract}
Summary We conducted a case-control study to examine osteonecrosis $(\mathrm{ON})$ incidence, patient characteristics, and selected potential risk factors using two health record databases in the UK. Statistically significant risk factors for ON included systemic corticosteroid use, hospitalization, referral or specialist visit, bone fracture, any cancer, osteoporosis, connective tissue disease, and osteoarthritis.

Introduction The purpose of this case-control study was to examine the incidence of osteonecrosis $(\mathrm{ON})$, patient characteristics, and selected potential risk factors for $\mathrm{ON}$ using two health record databases in the UK: the General
\end{abstract}

C. Cooper

Rheumatology, University of Southampton,

Southampton, UK

C. Cooper

MRC Epidemiology Resource Centre,

University of Southampton,

Southampton, UK

C. Cooper

Institute of Musculoskeletal Science, University of Oxford,

Oxford, UK

M. Steinbuch $(\bowtie) \cdot$ R. Stevenson $\cdot$ R. Miday

Pharmacovigilance and Epidemiology,

Procter \& Gamble Company,

Mason, OH 45040, USA

e-mail: steinbuch.m@pg.com

\section{N. B. Watts}

Bone Health and Osteoporosis Center, University of Cincinnati

College of Medicine,

Cincinnati, OH 45219, USA
Practice Research Database and The Health Improvement Network.

Methods ON cases $(n=792)$ were identified from 1989 to 2003 and individually matched (age, sex, and medical practice) up to six controls $(n=4,660)$ with no record of ON. Possible risk factors were considered for inclusion based on a review of published literature. Annual incidence rates were computed, and a multivariable logistic regression model was derived to evaluate selected risk factors.

Results ON of the hip represented the majority of cases (75.9\%). Statistically significant risk factors for ON were systemic corticosteroid use in the previous 2 years, hospitalization, referral or specialist visit, bone fracture, any cancer, osteoporosis, connective tissue disease, and osteoarthritis within the past 5 years. Only $4.4 \%$ of ON cases were exposed to bisphosphonates within the previous 2 years.

Conclusions This study provides further perspective on the descriptive epidemiology of ON. Studies utilizing more recent data may further elucidate the understanding of $\mathrm{ON}$ key predictors.

Keywords Avascular necrosis · Epidemiology

Osteonecrosis $\cdot$ Risk factors

\section{Introduction}

Osteonecrosis $(\mathrm{ON})$, also known as avascular necrosis and aseptic necrosis, is defined as bone cell death following a compromise of blood flow to the bone. ON is most common in the femoral head (i.e., hip) but can occur at any skeletal site (e.g., knee, shoulder, and ankle) [1,2]. The majority of ON cases are secondary to trauma [1]. Nontraumatic ON can also occur, but the underlying pathology 
is unclear $[1,3]$. In published literature, non-traumatic $\mathrm{ON}$ has been associated with a number of risk factors including corticosteroid use, alcohol consumption, immunosuppressive therapy, autoimmune diseases such as systemic lupus erythematosus and rheumatoid arthritis, hematologic/thrombotic disorders, malignancies and metabolic disorders such as diabetes mellitus, and renal failure [1, 3-5]. Patients who experience non-traumatic $\mathrm{ON}$ usually have more than one risk factor, which indicates the pathogenesis of non-traumatic ON is probably multifactorial [2].

The majority of studies to date have assessed risk factors for $\mathrm{ON}$ in specific diseases with corticosteroid use, e.g., systemic lupus erythematosus and organ transplantation [4-7]. Few studies have been conducted in a general population [3, 8]. The purpose of this study was to examine the incidence of $\mathrm{ON}$, patient characteristics, and selected potential risk factors for ON in two general population health record databases in the UK: the General Practice Research Database (GPRD) and The Health Improvement Network (THIN) database.

\section{Methods}

Study population and databases

The GPRD database contains computerized information entered by approximately 450 general practitioners in the UK. Data on approximately 3.4 million active patients (total of approximately 13 million) are systematically recorded, anonymized, and sent to GPRD where the data are collated and organized for research purposes. Symptoms and diagnoses are coded using the Oxford Medical Information
System (OXMIS) and the READ clinical classification system. The THIN database contains similar information entered by general practitioners in the UK and contains information on over six million patients from 358 general practice offices, including data on approximately 2.8 million active patients.

Only data from medical practices that passed quality control checks are included in the GPRD database [9]. Both the GPRD and THIN databases have been validated in several independent studies [10-14]. Both databases use the READ classification to code specific diagnoses; a drug dictionary based on the MULTILEX classification is used to code drugs. Information collected in both of the databases includes patient demographics and records of primary care visits as well as diagnoses from specialist referrals, hospital admissions, and the results of laboratory, radiographic, and diagnostic tests. Prescriptions issued by general practitioners are also recorded. Practices selected from THIN did not contribute to the GPRD during the study period, thereby avoiding duplication of ON cases.

Each database was screened for all permanently registered adults (aged 18 years or older) from 1989 to 2003. ON was defined as a patient with a record of at least one of the READ codes listed in Table 1. For each identified case, the first record of ON during the period of data collection was considered the index date. Within each database, each case was matched to up to six controls with no record of $\mathrm{ON}$. The matching criteria included age ( \pm 5 years), sex, and medical practice (registered at the same practice at the index date of the case). The index date of each control patient was assigned the same date as the corresponding matched case. Cases and controls were required to have a
Table 1 List of READ/OXMIS codes used for identifying osteonecrosis cases

\begin{tabular}{lll}
\cline { 2 - 3 } $\begin{array}{l}\text { Table } 1 \text { List of READ/OXMIS } \\
\text { codes used for identifying } \\
\text { osteonecrosis cases }\end{array}$ & READ/OXMIS code & Description \\
\cline { 2 - 3 } & $7201 \mathrm{NB}$ & Necrosis bone \\
$7239 \mathrm{AF}$ & Femur head avascular necrosis \\
& $7239 \mathrm{AH}$ & Hip avascular necrosis \\
& $9906 \mathrm{ON}$ & Osteoradio necrosis \\
$\mathrm{N} 334000$ & Avascular necrosis of bone, site unspecified \\
$\mathrm{N} 334100$ & Avascular necrosis of the head of humerus \\
$\mathrm{N} 334200$ & Avascular necrosis of the head of femur \\
& $\mathrm{N} 334300$ & Avascular necrosis of the medial femoral condyle \\
& $\mathrm{N} 334311$ & Femoral condylar avascular necrosis \\
& $\mathrm{N} 334400$ & Avascular necrosis of the talus \\
& $\mathrm{N} 334500$ & Avascular necrosis of capitellum \\
& $\mathrm{N} 334600$ & Avascular necrosis of lateral femoral condyle \\
& $\mathrm{N} 334700$ & Avascular necrosis of other bone \\
& $\mathrm{N} 334800$ & Idiopathic aseptic necrosis of bone \\
& $\mathrm{N} 334900$ & Osteonecrosis due to drugs \\
$\mathrm{N} 334 \mathrm{~A} 00$ & Osteonecrosis due to previous trauma \\
& $\mathrm{N} 334 \mathrm{z} 00$ & Avascular bone necrosis NOS
\end{tabular}


minimum of 3 months (i.e., 91 days) enrollment prior to the index date.

The overall study design was a case-control study that combined information from each of the two databases (GPRD and THIN). Cases with a diagnosis of ON were further assessed by examining the free text fields with key search terms for each subject. After identifying all diagnoses of $\mathrm{ON}$, the incidence of $\mathrm{ON}$ was computed over time, and analyses were carried out to explore potential risk factors for $\mathrm{ON}$.

\section{Statistical methods and analysis}

Incidences were calculated using midyear population counts. Possible risk factors, selected a priori, were considered for inclusion based on a review of the potential risk factors previously cited in the published literature [1, 4-7, 15]. Risk factors of interest included (1) drug exposure (including systemic corticosteroids, immunosuppressants, anti-infectives, bisphosphonates, statins, and hormone replacement therapy (HRT; women only)) in the 2 years prior to the index date and (2) medical history (including hospitalization, referral or specialist visit, bone fracture, any cancer including hematological cancer, inflammatory bowel disease (IBD), gout, solid organ or bone transplantation, asthma, renal failure or dialysis, congenital or acquired hip dislocation, diabetes mellitus, osteoporosis, connective tissue disease, and osteoarthritis) in the 5 years prior to the index date. Each of these potential risk factors was separately entered into a regression model.
Additionally, alcohol consumption was considered (depending on the proportion of subjects with data for this variable). Baseline demographic characteristics for cases and controls were compared.

Crude odds ratios (ORs) and 95\% confidence intervals (CIs) were calculated for each risk factor in a univariate analysis using conditional logistic regression, comparing cases and controls. After excluding risk factors that had an insignificant OR or did not reach an overall $1 \%$ prevalence, a final, multivariable logistic regression model was derived.

\section{Results}

A total of 792 cases and 4,660 controls were included in the analysis, with $99 \%$ of cases having at least five matched controls. Fifty-three percent of the cases and $53.1 \%$ of the controls were female, with a mean age of 57.5 years among cases and 57.6 years among controls. Mean observation time was 8.9 person-years for cases and 9.4 person-years for controls. The most common site of ON was the hip, representing $75.9 \%$ of the cases (Table 2 ).

The age-adjusted annual incidence rates of ON by sex and the osteonecrosis incidence rates by sex and age cohort are shown in Figs. 1 and 2. Overall, the recorded incidence of $\mathrm{ON}$ increased over time from approximately 1.4/100,000 in 1989 to approximately 3/100,000 in 2003. The incidence of $\mathrm{ON}$ in women was higher than men from 1989 to 1998; however, from 1999 through 2003, there was a shift to men having a higher incidence than women
Table 2 Baseline characteristics of cases and controls

\footnotetext{
${ }^{\text {a }}$ Other sites ( $\leq 5$ cases each) included head of humerus, medial femoral condyle, talus, femoral condylar, larynx, pelvis, rib, temp bone, and tibia

$S D$ standard deviation; IQR interquartile range; NOS not otherwise specified
}

\begin{tabular}{lccc}
\hline & Cases $(N=792)$ & Controls $(N=4,660)$ & Overall $(N=5,452)$ \\
\hline Sex & & & \\
Female & $420(53.0 \%)$ & $2,473(53.1 \%)$ & $2,893(53.1 \%)$ \\
Male & $372(47.0 \%)$ & $2,187(46.9 \%)$ & $2,559(46.9 \%)$ \\
Age (years) & & & \\
Mean (SD) & $57.5(18.99)$ & $57.6(18.90)$ & $57.6(18.91)$ \\
Median (IQR) & $58.5(42.0-73.0)$ & $59.0(42.0-73.0)$ & $59.0(42.0-73.0)$ \\
Person-years of observation) & & \\
Mean (SD) & $8.9(4.1)$ & $9.4(4.0)$ & $9.4(4.0)$ \\
Median (IQR) & $9.3(5.9-11.8)$ & $9.7(6.3-12.5)$ & $9.7(6.2-12.5)$ \\
Site of osteonecrosis & & & $601(11.0 \%)$ \\
Hip & $601(75.9 \%)$ & $0(0.0 \%)$ & $36(0.7 \%)$ \\
Wrist & $36(4.5 \%)$ & $0(0.0 \%)$ & $20(0.4 \%)$ \\
Knee & $20(2.5 \%)$ & $0(0.0 \%)$ & $18(0.3 \%)$ \\
Shoulder & $18(2.3 \%)$ & $0(0.0 \%)$ & $15(0.3 \%)$ \\
Foot & $15(1.9 \%)$ & $0(0.0 \%)$ & $13(0.2 \%)$ \\
Ankle & $13(1.7 \%)$ & $0(0.0 \%)$ & $3(0.1 \%)$ \\
Jaw & $3(0.4 \%)$ & $0(0.0 \%)$ & $20(0.4 \%)$ \\
Other & $20(2.5 \%)$ & $0(0.0 \%)$ & $66(1.2 \%)$ \\
NOS & $66(8.3 \%)$ & $0(0.0 \%)$ & \\
\hline
\end{tabular}


Fig. 1 Age-adjusted annual incidence rates by sex (GPRD and THIN research databases)

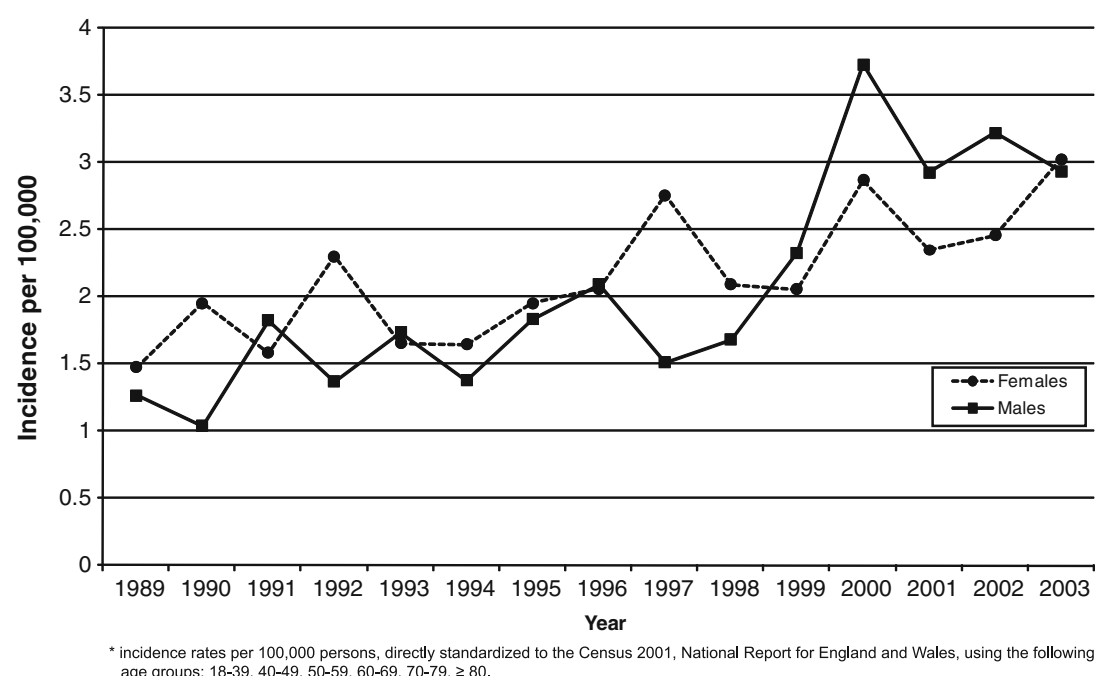

age groups: $18-39,40-49,50-59,60-69,70-79, \geq 80$.
(Fig. 1). Overall and for women, the incidence of $\mathrm{ON}$ increased with age. The incidence of $\mathrm{ON}$ in men remained constant from age 40 to 79 (around 2/100,000), increasing to 3/100,000 at age 80 years and older. From ages 18-59, men had a higher incidence than women; however, women 60 years and older had a higher incidence than men (Fig. 2).

Table 3 shows descriptive statistics for each of the potential risk factors of interest. Drug exposure was captured over the prior 2-year period and classified a priori, as follows: None; Exposed $(2+$ prescriptions within 120 days in the previous 2 years); or Intermittent (all other possible exposure scenarios). In the study population, anti-infectives were the most commonly prescribed therapy $(22.9 \%$ among cases and $15.3 \%$ among controls). Relevant medical history was captured for the previous 5 years. The most commonly reported disease condition was osteoarthritis in $21.7 \%$ of cases and $7.8 \%$ of controls. A large proportion of subjects were missing data for alcohol consumption $(46.3 \%$ of cases and $51.2 \%$ of controls; Table 3 ), and it was, therefore, decided to exclude this variable from multivariable modeling (Tables 4 and 5).

Statistically elevated crude ORs were observed for bisphosphonates, systemic corticosteroids, immunosuppressants (intermittent only), anti-infectives, and HRT (exposed only; Table 4). Marked differences between cases and controls were noted for hospitalization, referral or specialist visit, and bone fracture in the prior 5-year period, and, despite a relatively small proportion of exposed subjects, the crude ORs were also significantly increased for cancer, IBD, gout, solid organ or bone transplantation, asthma, renal failure or dialysis, osteoporosis, connective tissue disease, and osteoarthritis (Table 4). Statistically significant
Fig. 2 Osteonecrosis incidence rates by sex and age cohort (1989-2003). Incidence rates are weighted average of the annual sex- and age-cohort-specific incidence rates (GPRD and THIN research databases)

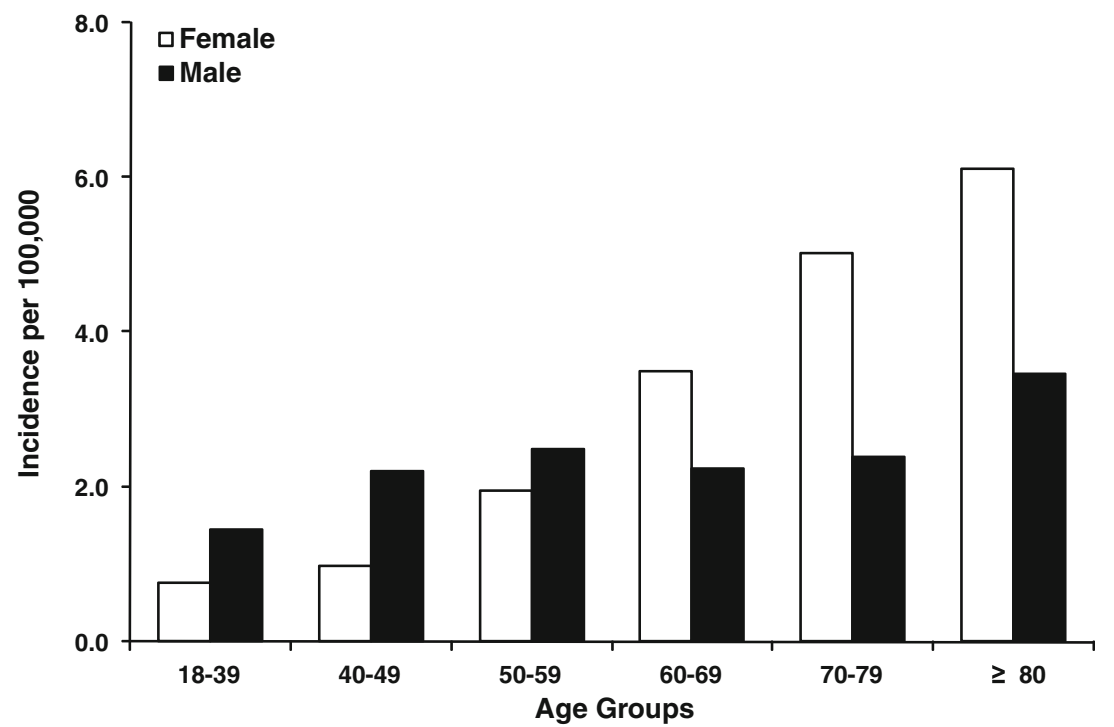


Table 3 Potential risk factors of interest

\begin{tabular}{|c|c|c|c|}
\hline Variable & Cases $(N=792)$ & Controls $(N=4660)$ & $p$-value \\
\hline \multicolumn{4}{|l|}{ Drug exposures of interest (within the past 2 years) } \\
\hline \multicolumn{4}{|l|}{ Bisphosphonates } \\
\hline None & $757(95.6 \%)$ & $4,607(98.9 \%)$ & $<.01$ \\
\hline Intermittent & $26(3.3 \%)$ & $31(0.7 \%)$ & $<.01$ \\
\hline Exposed & $9(1.1 \%)$ & $22(0.5 \%)$ & .02 \\
\hline \multicolumn{4}{|l|}{ Systemic corticosteroids } \\
\hline None & $648(81.8 \%)$ & $4,422(94.9 \%)$ & $<.01$ \\
\hline Intermittent & $108(13.6 \%)$ & $187(4.0 \%)$ & $<.01$ \\
\hline Exposed & $36(4.5 \%)$ & $51(1.1 \%)$ & $<.01$ \\
\hline \multicolumn{4}{|l|}{ Immunosuppressants } \\
\hline None & $757(95.6 \%)$ & $4,643(99.6 \%)$ & $<.01$ \\
\hline Intermittent & $32(4.0 \%)$ & $12(0.3 \%)$ & $<.01$ \\
\hline Exposed & $3(0.4 \%)$ & $5(0.1 \%)$ & .07 \\
\hline \multicolumn{4}{|l|}{ Anti-infectives } \\
\hline None & $372(47.0 \%)$ & $2,787(59.8 \%)$ & $<.01$ \\
\hline Intermittent & $239(30.2 \%)$ & $1,162(24.9 \%)$ & $<.01$ \\
\hline Exposed & $181(22.9 \%)$ & $711(15.3 \%)$ & $<.01$ \\
\hline \multicolumn{4}{|l|}{ Statins } \\
\hline None & $780(98.5 \%)$ & $4,530(97.2 \%)$ & .04 \\
\hline Intermittent & $11(1.4 \%)$ & $110(2.4 \%)$ & .09 \\
\hline Exposed & $1(0.1 \%)$ & $20(0.4 \%)$ & .20 \\
\hline \multicolumn{4}{|l|}{ HRT (women only) } \\
\hline None & $374(89.0 \%)$ & $2,285(92.4 \%)$ & .02 \\
\hline Intermittent & $18(4.3 \%)$ & $88(3.6 \%)$ & .46 \\
\hline Exposed & $28(6.7 \%)$ & $100(4.0 \%)$ & .02 \\
\hline \multicolumn{4}{|l|}{ Medical history in the 5 years prior } \\
\hline Hospitalization & $267(33.7 \%)$ & $790(17.0 \%)$ & $<.01$ \\
\hline Referral or specialist visit & $401(50.6 \%)$ & $1,563(33.5 \%)$ & $<.01$ \\
\hline Bone fracture & $175(22.1 \%)$ & $213(4.6 \%)$ & $<.01$ \\
\hline Any cancer (includes hematological cancer) & $31(3.9 \%)$ & $53(1.1 \%)$ & $<.01$ \\
\hline IBD & $14(1.8 \%)$ & $12(0.3 \%)$ & $<.01$ \\
\hline Gout & $17(2.1 \%)$ & $40(0.9 \%)$ & $<.01$ \\
\hline Solid organ or bone marrow transplantation & $5(0.6 \%)$ & $2(0.0 \%)$ & $<.01$ \\
\hline Asthma & $56(7.1 \%)$ & $202(4.3 \%)$ & $<.01$ \\
\hline Renal failure or dialysis & $11(1.4 \%)$ & $4(0.1 \%)$ & $<.01$ \\
\hline Congenital or acquired hip dislocation & $2(0.3 \%)$ & $2(0.0 \%)$ & .02 \\
\hline Diabetes mellitus & $19(2.4 \%)$ & $135(2.9 \%)$ & .43 \\
\hline Osteoporosis & $29(3.7 \%)$ & $44(0.9 \%)$ & $<.01$ \\
\hline Connective tissue disease & $52(6.6 \%)$ & $68(1.5 \%)$ & $<.01$ \\
\hline Osteoarthritis & $172(21.7 \%)$ & $363(7.8 \%)$ & $<.01$ \\
\hline \multicolumn{4}{|l|}{ Alcohol consumption } \\
\hline Missing & $367(46.3 \%)$ & $2,387(51.2 \%)$ & .01 \\
\hline Non-drinker & $69(8.7 \%)$ & $422(9.1 \%)$ & .75 \\
\hline Light drinker & $251(31.7 \%)$ & $1,441(30.9 \%)$ & .67 \\
\hline Moderate drinker & $78(9.8 \%)$ & $342(7.3 \%)$ & .01 \\
\hline Heavy/very heavy drinker & $27(3.4 \%)$ & $68(1.4 \%)$ & .11 \\
\hline
\end{tabular}

$I B D$ inflammatory bowel disease; HRT hormone replacement therapy

Exposed is defined as $2+$ prescriptions within 120 days in the past 2 years; intermittent is defined as all other exposure scenarios 
risk factors for $\mathrm{ON}$ from the final multivariable logistic regression model were systemic corticosteroid use (intermittent and exposed), hospitalization, referral or specialist visit, bone fracture, any cancer, osteoporosis, connective tissue disease, and osteoarthritis (Table 4).

An additional analysis was performed in the subset of cases with hip $\mathrm{ON}$ and their matched controls because these represented a potentially more homogeneous population and also included the majority (75.9\%) of the identified ON cases overall (Table 2). A total of 601 cases and 3,533 controls were included in the hip ON subset analysis. Approximately $54 \%$ of cases and controls in the hip ON subset were female with a mean age of 58.3 years. Statistically significant risk factors for hip ON from the adjusted multivariable logistic regression model were the same as the overall ON population except for the inclusion
Table 4 Multivariable logistic regression modeling: selected potential risk factors of osteonecrosis at any site
$O R$ odds ratio; $I B D$ inflammatory bowel disease; $H R T$ hormone replacement therapy; Exposed 2+ prescriptions within 120 days in the past 2 years; Intermittent all other exposure scenarios

${ }^{a}$ The final multivariable logistic regression model was adjusted for bisphosphonates, systemic corticosteroids, anti-infectives, hospitalization, referral or specialist visit, bone fracture, any cancer, gout, asthma, osteoporosis, connective tissue disease, and osteoarthritis

${ }^{\mathrm{b}}$ Variables excluded from the final regression model based on either not reaching $1 \%$ overall prevalence or crude OR was not statistically significant

${ }^{\mathrm{c}}$ HRT was excluded from the final regression model in order to retain the full sample (men and women)

\begin{tabular}{|c|c|c|}
\hline Variable & Crude OR $(95 \% \mathrm{CI})$ & Adjusted $^{\mathrm{a}}$ OR $(95 \% \mathrm{CI})$ \\
\hline \multicolumn{3}{|l|}{ Drug exposures of interest (within the past 2 years) } \\
\hline \multicolumn{3}{|l|}{ Bisphosphonates } \\
\hline Intermittent & $5.5(3.21,9.53)$ & $1.4(0.68,2.87)$ \\
\hline Exposed & $2.8(1.26,6.07)$ & $1.1(0.40,3.03)$ \\
\hline \multicolumn{3}{|l|}{ Systemic corticosteroids } \\
\hline Intermittent & $4.1(3.17,5.27)$ & $3(2.15,4.05)$ \\
\hline Exposed & $5.3(3.42,8.33)$ & $3.4(1.95,5.82)$ \\
\hline \multicolumn{3}{|l|}{ Immunosuppressants } \\
\hline Intermittent & $15.6(8.03,30.30)$ & $-{ }^{b}$ \\
\hline Exposed & $3.5(0.84,14.73)$ & $-{ }^{b}$ \\
\hline \multicolumn{3}{|l|}{ Anti-infectives } \\
\hline Intermittent & $1.6(1.36,1.95)$ & $1.2(0.98,1.47)$ \\
\hline Exposed & $2.1(1.69,2.57)$ & $1.2(0.95,1.55)$ \\
\hline \multicolumn{3}{|l|}{ Statins } \\
\hline Intermittent & $0.6(0.29,1.05)$ & $-{ }^{\mathrm{b}}$ \\
\hline Exposed & $0.3(0.04,2.15)$ & $-{ }^{b}$ \\
\hline \multicolumn{3}{|l|}{ HRT (women only) } \\
\hline Intermittent & $1.3(0.78,2.30)$ & $-^{\mathrm{c}}$ \\
\hline Exposed & $1.9(1.20,3.12)$ & $-^{\mathrm{c}}$ \\
\hline \multicolumn{3}{|l|}{ Medical history in the 5 years prior } \\
\hline Hospitalization & $3.4(2.80,4.19)$ & $1.8(1.41,2.25)$ \\
\hline Referral or specialist visit & $3.6(2.88,4.44)$ & $2.2(1.74,2.85)$ \\
\hline Bone fracture & $6.5(5.13,8.15)$ & $5.8(4.43,7.49)$ \\
\hline Any cancer, including hematological cancer & $3.6(2.29,5.75)$ & $3.5(2.05,5.82)$ \\
\hline IBD & $7.3(3.30,16.10)$ & $-\mathrm{b}$ \\
\hline Gout & $2.7(1.49,4.84)$ & $1.9(0.95,3.63)$ \\
\hline Solid organ or bone transplantation & $15(2.91,77.31)$ & ${ }^{\mathrm{b}}$ \\
\hline Asthma & $1.7(1.26,2.34)$ & $0.9(0.62,1.33)$ \\
\hline Renal failure or dialysis & $16.5(5.25,51.81)$ & $-\mathrm{b}$ \\
\hline Congenital or acquired hip dislocation & $6(0.85,42.71)$ & $-{ }^{b}$ \\
\hline Diabetes mellitus & $0.8(0.51,1.34)$ & $-{ }^{b}$ \\
\hline Osteoporosis & $4.3(2.60,6.99)$ & $2.1(1.07,4.23)$ \\
\hline Connective tissue disease & $4.9(3.37,7.14)$ & $2.6(1.65,4.11)$ \\
\hline Osteoarthritis & $4.1(3.26,5.13)$ & $4.1(3.16,5.28)$ \\
\hline \multicolumn{3}{|l|}{ Alcohol consumption } \\
\hline Missing & $0.9(0.67,1.21)$ & \\
\hline Light drinker & $1.1(0.81,1.47)$ & \\
\hline Moderate drinker & $1.5(1.03,2.17)$ & \\
\hline Heavy/very heavy drinker & $2.6(1.54,4.46)$ & \\
\hline
\end{tabular}


Table 5 Multivariable logistic regression modeling: selected potential risk factors for osteonecrosis of the hip (subset $N=4134$ )

$N=601$ cases and 3,533 controls

$O R$ odds ratio; $I B D$ inflammatory bowel disease; HRT hormone replacement therapy, Exposed $2+$ prescriptions within 120 days in the past 2 years; Intermittent all other exposure scenarios

${ }^{\mathrm{a}}$ The final multivariable logistic regression model was adjusted for bisphosphonates, systemic corticosteroids, immunosuppressants, anti-infectives, hospitalization, referral or specialist visit, bone fracture, any cancer, gout, asthma, osteoporosis, connective tissue disease, and osteoarthritis

${ }^{\mathrm{b}}$ Variables excluded from the final regression model based on either not reaching $1 \%$ overall prevalence or crude OR was not statistically significant

${ }^{\mathrm{c}}$ HRT was excluded from the final regression model in order to retain the full sample (men and women)

\begin{tabular}{|c|c|c|}
\hline Risk factor & Crude OR $(95 \%$ CI) & Adjusted $^{\mathrm{a}}$ OR $(95 \% \mathrm{CI})$ \\
\hline \multicolumn{3}{|l|}{ Drug exposures of interest (within the past 2 years) } \\
\hline \multicolumn{3}{|l|}{ Bisphosphonates } \\
\hline Intermittent & $6(3.24,11.15)$ & $1.7(0.37,7.72)$ \\
\hline Exposed & $3.1(1.17,8.20)$ & $0.7(0.11,4.25)$ \\
\hline \multicolumn{3}{|l|}{ Systemic corticosteroids } \\
\hline Intermittent & $4.2(3.12,5.58)$ & $3.1(1.93,4.95)$ \\
\hline Exposed & $4.8(2.84,7.98)$ & $3(1.37,6.44)$ \\
\hline \multicolumn{3}{|l|}{ Immunosuppressants } \\
\hline Intermittent & $22.4(9.76,51.54)$ & $6(1.94,18.38)$ \\
\hline Exposed & $2.3(0.45,12.05)$ & $1.1(0.07,16.52)$ \\
\hline \multicolumn{3}{|l|}{ Anti-infectives } \\
\hline Intermittent & $1.6(1.26,1.91)$ & $1.1(0.79,1.40)$ \\
\hline Exposed & $1.7(1.37,2.22)$ & $1.2(0.82,1.65)$ \\
\hline \multicolumn{3}{|l|}{ Statins } \\
\hline Intermittent & $0.7(0.32,1.36)$ & $-{ }^{\mathrm{b}}$ \\
\hline Exposed & $0(0)$ & $-{ }^{\mathrm{b}}$ \\
\hline \multicolumn{3}{|l|}{ HRT (women only) } \\
\hline Intermittent & $1.1(0.58,2.27)$ & $-{ }^{\mathrm{c}}$ \\
\hline Exposed & $1.7(0.97,3.15)$ & $-^{\mathrm{c}}$ \\
\hline \multicolumn{3}{|l|}{ Medical history in the 5 years prior } \\
\hline Hospitalization & $3.3(2.61,4.13)$ & $2(1.43,2.80)$ \\
\hline Referral or specialist visit & $3.2(2.53,4.14)$ & $2.1(1.50,3.07)$ \\
\hline Bone fracture & $6.5(4.94,8.47)$ & $5.8(3.96,8.56)$ \\
\hline Any cancer, including hematological cancer & $3.2(1.88,5.55)$ & $2.8(1.20,6.31)$ \\
\hline IBD & $10.5(4.19,26.50)$ & $-{ }^{\mathrm{b}}$ \\
\hline Gout & $2.8(1.47,5.41)$ & $2.3(0.85,6.37)$ \\
\hline Solid organ or bone transplantation & $24(2.68,214.68)$ & $-{ }^{\mathrm{b}}$ \\
\hline Asthma & $1.8(1.25,2.57)$ & $1(0.55,1.73)$ \\
\hline Renal failure or dialysis & $32.9(7.31,148.49)$ & $-{ }^{\mathrm{b}}$ \\
\hline Congenital or acquired hip dislocation & $6(0.85,42.71)$ & $-{ }^{\mathrm{b}}$ \\
\hline Diabetes mellitus & $0.8(0.44,1.36)$ & $-{ }^{\mathrm{b}}$ \\
\hline Osteoporosis & $3.9(2.23,6.98)$ & $2.8(0.93,8.35)$ \\
\hline Connective tissue disease & $5.6(3.69,8.64)$ & $2.5(1.19,5.39)$ \\
\hline Osteoarthritis & $4.3(3.35,5.53)$ & $5(3.51,7.02)$ \\
\hline \multicolumn{3}{|l|}{ Alcohol consumption } \\
\hline Missing & $0.9(0.67,1.33)$ & \\
\hline Light drinker & $1.1(0.78,1.54)$ & \\
\hline Moderate drinker & $1.4(0.94,2.22)$ & \\
\hline Heavy/very heavy drinker & $2.7(1.47,5.03)$ & \\
\hline
\end{tabular}

of immunosuppressant use (intermittent) and the exclusion of osteoporosis (Table 5).

Of recent interest is the use of bisphosphonates and a postulated association with osteonecrosis of the jaw (ONJ) [16-19]. In our case-control study, only $4.4 \%$ of ON cases were bisphosphonate users within the previous 2 years (Table 3). Across all cases, only three had the jaw mentioned as the site of $\mathrm{ON}$, and none of them had been exposed to bisphosphonates (Table 2).
Table 6 reports the type of bisphosphonate exposure for cases and controls in this study. Etidronate was the most common compound reported; this was the only oral bisphosphonate marketed for the treatment of osteoporosis in the UK in the early 1990s. Further, the distribution by type of bisphosphonate is overall consistent with market share in the UK during the study period. No cases or controls with intravenous bisphosphonate use were identified in this study. Exposure to bisphosphonates was not 
Table 6 Types of bisphosphonates used by cases and controls within the previous 2-year study period

\begin{tabular}{llll}
\hline Type of bisphosphonate & Cases $(N=792)$ & Controls $(N=4660)$ & Overall $(N=5452)$ \\
\hline Alendronate only & $9(26 \%)$ & $9(17 \%)$ & $18(20 \%)$ \\
Clodronate only & $1(3 \%)$ & $0(0 \%)$ & $1(1 \%)$ \\
Etidronate only & $20(57 \%)$ & $42(79 \%)$ & $62(70 \%)$ \\
Risedronate only & $2(6 \%)$ & $1(2 \%)$ & $3(3 \%)$ \\
Alendronate and risedronate & $1(3 \%)$ & $0(0 \%)$ & $1(1 \%)$ \\
Alendronate and etidronate & $1(3 \%)$ & $1(2 \%)$ & $2(2 \%)$ \\
Alendronate, etidronate, and risedronate & $1(3 \%)$ & $0(0 \%)$ & $1(1 \%)$ \\
Total number of cases/controls & 35 & 53 & 88 \\
\hline
\end{tabular}

associated with an increased risk of $\mathrm{ON}$ in the adjusted model of all skeletal sites combined (Table 4) or in the adjusted model for the hip subset (Table 5).

\section{Discussion}

From 1989 to 2003, in this study population, the observed incidence of $\mathrm{ON}$ ranged from approximately 1.4-3.0/ 100,000 within the combined GPRD/THIN dataset. The reason for the increased incidence over time is not known but could be due in part to the increasing use of more advanced radiographic techniques, especially MRI, that are more sensitive in detecting ON. Consistent with the literature $[1,5]$, we found that the hip was the most commonly diagnosed site for ON (75.9\%) and that corticosteroid use was associated with a 3-fold increased risk for ON. Significant risk factors for ON at all skeletal sites combined did not differ substantially from those for ON of the hip. While we did not assess trauma specifically, bone fracture in the prior 5 years was associated with a 5.8fold increased risk of $\mathrm{ON}$ at all skeletal sites both combined and at the hip.

As observed in other studies, a history of connective tissue disease or cancer were significant risk factors for $\mathrm{ON}$. This may be confounded by the frequent use of corticosteroids in these populations [4-6, 20]. In addition, overall disease severity/morbidity may also contribute to a higher rate of $\mathrm{ON}$ in these populations $[1,4]$. There were two risk factors that showed a risk reduction $(70 \%$ with statin use and $60 \%$ with diabetes mellitus); however, neither was statistically significant and neither met the criteria for inclusion in the multivariable model.

Our study population was $53 \%$ female. This contrasts with previous findings that $\mathrm{ON}$ is more common in men in the general population (with the exception of systemic lupus erythematosus populations) [1]. In addition, the age of our study population ranged between 42 and 73 years (mean $=57.6$ years; median $=59.0$ years), which is older than previously reported in the literature $[1,21]$.
Although a history of osteoporosis in the prior 5 years was a significant risk factor in this study, bisphosphonate use was not. Only three cases had the jaw mentioned as the site of $\mathrm{ON}$, and none of these had been exposed to bisphosphonates in the previous 2 years. In this study, there were no cases of $\mathrm{ON}$ with intravenous bisphosphonate use, which has been reported with ONJ in the treatment of multiple myeloma and metastatic carcinoma in the literature [16-19]. It should also be noted that the study period was prior to the recent literature and recent awareness of ONJ. Given that prior bone fracture was the strongest risk factor observed in this study and that bisphosphonates are indicated for the prevention and treatment of osteoporosis that is often first identified after a fracture occurs, confounding by indication may explain the observation of bisphosphonate use and $\mathrm{ON}$ in the univariate analysis (elevated crude OR).

There are several limitations to this study. As with the use of any medical records database, misclassification bias is possible. The case definition was developed to include all available READ codes in order to minimize the likelihood that true cases of ON were missed (i.e., sensitive) and that cases were not falsely classified (i.e., specific). Some cases of $\mathrm{ON}$ may not have been recorded or diagnosed; the diagnosis of non-traumatic $\mathrm{ON}$ is difficult because the disease is silent until pain presents [1]. In general, cases of ONJ identified by dental professionals may not be consistently recorded in the medical records databases. Further, ONJ had no separate READ code during the study period. To address this limitation, possible cases were assessed from a review of the text fields for $\mathrm{ON}$ cases with any mention of "jaw." Another limitation is that prescriptions written by specialists may not have been recorded by the general practitioner. The study design was based on an a priori selection of risk factors that have been previously cited in the literature [1, 4-7, 15] with particular focus on those that were highly correlated; therefore, this study may have excluded other potentially important risk factors.

In conclusion, using data from the UK GPRD and THIN databases, we found that significant predictors of $\mathrm{ON}$ at any skeletal site included use of systemic corticosteroids in the 
previous 2 years, hospitalization, referral or specialist visit, bone fracture, any cancer, osteoporosis, connective tissue disease, and osteoarthritis within the past 5 years. Bisphosphonate use was not a significant predictor of ON. This study aimed to provide a broader perspective on the descriptive epidemiology of ON risk factors than previous published studies. Studies utilizing more recent data may further elucidate the understanding of key predictors of $\mathrm{ON}$.

Acknowledgments The authors gratefully acknowledge the following people for their statistical, editorial, and clinical expertise in the preparation of this manuscript: Karen Driver, Diane Vonderheide, Emma Hobbs, Andrea Klemes, Coridad Pontes and J. Michael Sprafka.

Conflicts of interest Professor Cooper has undertaken consultancy and lecturing commitments for the Alliance for Better Bone Health, Eli Lilly, Novartis, GSK Roche, Servier, MSD, and Amgen. Dr. Steinbuch and Mr. Stevenson are employed by Procter \& Gamble. Dr. Miday retains stock in Procter \& Gamble. Dr. Watts has received honoraria for lectures from Amgen, Novartis, Procter \& Gamble, and Sanofi-Aventis; consulting fees from Amgen, Eli Lilly, Novartis, Novo Nordisk, Procter \& Gamble, and Sanofi-Aventis; and research support from Amgen, Eli Lilly, Novartis, and Procter \& Gamble.

Open Access This article is distributed under the terms of the Creative Commons Attribution Noncommercial License which permits any noncommercial use, distribution, and reproduction in any medium, provided the original author(s) and source are credited.

\section{References}

1. Assouline-Dayan Y, Chang C, Greenspan A, Shoenfeld Y, Gershwin ME (2002) Pathogenesis and natural history of osteonecrosis. Semin Arthritis Rheum 32(2):94-124

2. Tofferi JK, Gilliland W (2008) Avascular Necrosis. Available via eMedicine. http://emedicine.medscape.com/article/333364-overview. Accessed 20 Feb 2009.

3. Mont MA, Payman RK, Laporte DM, Petri M, Jones LC, Hungerford DS (2000) Atraumatic osteonecrosis of the humeral head. J Rheumatol 27(7):1766-73

4. Gladman DD, Urowitz MB, Chaudhry-Ahluwalia V, Hallet DC, Cook RJ (2001) Predictive factors for symptomatic osteonecrosis in patients with systemic lupus erythematosus. J Rheumatol 28 (4):761-5

5. Abu-Shakra M, Buskila D, Shoenfeld Y (2003) Osteonecrosis in patients with SLE. Clin Rev Allergy Immunol 25(1):13-24

6. Mok CC, Lau CS, Wong RW (1998) Risk factors for avascular bone necrosis in systemic lupus erythematosus. $\mathrm{Br} \mathrm{J}$ Rheumatol 37(8):895-900

7. Calvo-Alén J, McGwin G, Toloza S, Fernández M, Roseman JM, Bastian HM, Cepeda EJ, González EB, Baethge BA, Fessler BJ, Vilá LM, Reveille JD, Alarcón GS, LUMINA Study Group
(2006) Systemic lupus erythematosus in a multiethnic US cohort (LUMINA): XXIV. Cytotoxic treatment is an additional risk factor for the development of symptomatic osteonecrosis in lupus patients: results of a nested matched case-control study. Ann Rheum Dis 65(6):785-90

8. Etminan M, Aminzadeh K, Matthew IR, Brophy JM (2008) Use of oral bisphosphonates and the risk of aseptic osteonecrosis: a nested case-control study. J Rheumatol 35(4):691-5

9. van Staa TP, Cooper C, Leufkens HG, Bishop N (2003) Children and the risk of fractures caused by oral corticosteroids. J Bone Miner Res 18(5):913-8

10. van Staa TP, Abenhaim L (1994) The quality of information recorded on a UK database of primary care records: a study of hospitalization due to hypoglycemia and other conditions. Pharmacoepidemiol Drug Saf 3(1):15-21

11. van Staa TP, Abenhaim L, Cooper C, Zhang B, Leufkens HG (2000) The use of a large pharmacoepidemiological database to study exposure to oral corticosteroids and risk of fractures: validation of study population and results. Pharmacoepidemiol Drug Saf 9(5):359-66

12. Wurst KE, Ephross SA, Loehr J, Clark DW, Guess HA (2007) The utility of the general practice research database to examine selected congenital heart defects: a validation study. Pharmacoepidemiol Drug Saf 16(8):867-77

13. Thomas SL, Edwards CJ, Smeeth L, Cooper C, Hall AJ (2008) How accurate are diagnoses for rheumatoid arthritis and juvenile idiopathic arthritis in the general practice research database. Arthritis Rheum 59(9):1314-21

14. Lewis JD, Schinnar R, Bilker WB, Wang X, Strom BL (2007) Validation studies of the health improvement network (THIN) database for pharmacoepidemiology research. Pharmacoepidemiol Drug Saf 16(4):393-401

15. Fink JC, Leisenring WM, Sullivan KM, Sherrard DJ, Weiss NS (1998) Avascular necrosis following bone marrow transplantation: a case-control study. Bone 22(1):67-71

16. Rizzoli R, Burlet N, Cahall D, Delmas PD, Eriksen EF, Felsenberg D, Grbic J, Jontell M, Landesberg R, Laslop A, Wollenhaupt M, Papapoulos S, Sezer O, Sprafka M, Reginster JY (2008) Osteonecrosis of the jaw and bisphosphonate treatment for osteoporosis. Bone 42(5):841-7

17. Woo SB, Hellstein JW, Kalmar JR (2006) Systematic review: bisphosphonates and osteonecrosis of the jaws. Ann Intern Med 144(10):753-61

18. Ruggiero SL, Mehrotra B, Rosenberg TJ, Engroff SL (2004) Osteonecrosis of the jaws associated with the use of bisphosphonates: a review of 63 cases. J Oral Maxillofac Surg 62(5):527-34

19. Marx RE (2003) Pamidronate (Aredia) and zoledronate (Zometa) induced avascular necrosis of the jaws: a growing epidemic. J Oral Maxillofac Surg 61(9):1115-7

20. Talamo G, Angtuaco E, Walker RC, Dong L, Miceli MH, Zangari M, Tricot G, Barlogie B, Anaissie E (2005) Avascular necrosis of femoral and/or humeral heads in multiple myeloma: results of a prospective study of patients treated with dexamethasone-based regimens and high-dose chemotherapy. J Clin Oncol 23(22):5217-23

21. McKown K (2007) Osteonecrosis. Available via American College of Rheumatology. http://www.rheumatology.org/public/ factsheets/diseases_and_conditions/osteonecrosis.asp?aud=pat. Accessed 20 Feb 2009. 